\title{
Dossiê: a história do corpo
}

\section{Mary Lucy Murray Del Priore}

Departamento de História, Faculdade de Filosofia, Letras e Ciências Humanas/Universidade de São Paulo

"O que esculpimos na carne humana é uma imagem da sociedade" Mary Douglas
1.Veja-se a entrevista de Vinicius Torres Freire com o sociológo Lucien Sfez, sobre seu livro publicado pela editora Seuil, na Folba de $S$. Paulo, 7 de abril de 1996, Caderno Mais!, p.5-4 e 5-5.

Tirando a roupa...

Na sociedade ocidental existem temas e assuntos sobre os quais só falamos sussurrando. Em voz baixa. É de bom tom usarem-se metáforas quando se trata de doenças, regras, deflorações e deformações. Por outro lado, quando nossos pesquisadores lançam-se sobre as sociedades ditas arcaicas, nada os detém; a descrição da vida sexual dos "selvagens" acompanha-se, quase sempre, dos detalhes mais crus. Suas anomalias são minuciosamente anatomizadas.

Terá sido a crítica a essa excessiva "discreção" em relação aos contemporâneos que levou historiadores de diferentes formações metodológicas a interessarem-se pelo corpo? Terão sido empurrados pelo debate globalizante em torno das noções de "saúde"? Afinal, filhos do seu tempo, como os queria lucien Febvre, acompanham as discussões e pesquisas sobre biotecnologia, antitabagismo, extirpação preventiva de seios e terapias gênicas, sendo constantemente convidados a opinar sobre o que Lucien Sfez chamou de "a saúde perfeita": espécie de utopia pós-moderna, que promete "purificar todos os seres geneticamente defeituosos e o planeta, levando o homem de volta ao paraíso por meio da ciência"l. 
Lugar do desejo, da vida e da morte, o corpo pode tê-los atraído por sua fascinação ambígua, pela tensa relação que, enquanto objeto, ele exerce numa sociedade onde se morre miserável e doloridamente, de males cuja cura se está longe de alcançar (Del Priore 1994).

A História do corpo pode ser ainda uma singela filha do acaso. No prefácio à edição francesa de seu Making sex, body and gender from the Greecks to Freud, Thomas Laqueur (1990) afirma ter trabalhado, durante dez anos, sobre um tema que a princípio se lhe afigurava como "uma história mais ou menos linear do sexo". Acreditava, então, reconhecer uma longa duração braudeliana na representação corporal, que remontava aos gregos, quando os signos físicos da diferença sexual - genitais, órgãos internos, processos fisiológicos e orgasmos eram bem menos distintos do que se tornaram depois. Mas enganara-se. Corpos podem ser muito eloquentes e revelar mudanças nos ângulos de abordagem histórica, ajudando a melhor penetrar as realidades do passado.

Podemos invocar várias explicações para entender o porquê de uma História do corpo, ou simplesmente afirmar (como nos exames vestibulares), que "todas acima são válidas". Contudo, é preciso lembrar uma corrente fundamental a desnudar tal objeto: a vertente antropológica à qual, mais tarde, associar-se-á a Nouvelle Histoire.

Grandes etnólogos da atualidade, sobretudo aqueles que vieram depois de Marcel Griaule, mostraram que uma sociedade se estabelece sobre um sistema global de representações, unidas por correspondências, para nós, muitas vezes, irracionais, mas dotadas de uma lógica interna passivel de desvendamento. Como, então, ignorar a importância desses elementos de importância capital (os corpos), se eles asseguram a fecundidade, a reprodução, a doença ou a morte? Em um sistema de mundo no qual as correspondências se estendem do macrocosmo ao microcosmo, como negligenciar as relações simbólicas que poderiam conduzir, eventualmente, para além da simples descrição, a explicações imperiosamente reclamadas pelos hábitos lógicos de nossa cultura? Foi em contacto com os etnólogos que os historiadores perceberam a importância destas manifestações obscuras e em parte subterrâneas da vida em sociedade (lévi-Strauss 1983).

Oachado thes abriu uma época de esplendor. A partir de elementos que podiam parecer fragmentários, como os comportamentos físicos ou psicológicos, os sistemas de valores ou os sistemas simbólicos, as motivações conscientes ou inconscientes dos atores sociais, reconstituiam a realidade histórica em profundidade, em sua totalidade. Temas engenhosos e fascinantes passaram a atrair mais e mais leitores, capturados pela familiaridade entre instigantes objetos de estudo e o vivido histórico (Ribeiro 1994: 10). Neste cenário, o aporte mais imediato da etnologia à História do corpo veio por meio de estudos sobre o homem cotidiano.

Nesta fase de "pré-história" da História do corpo - lembra Jacques le Goff (1977: 335-348) -, era preciso dar especial atenção ao domínio da longa duração e do tempo quase imóvel dentro do qual se passou a estudar os fatos repetidos e esperados - cerimônias e ritos ligados à história biológica e familiar: nascimentos, casamentos e mortes. O corpo entrava em cena. Atendia, assim, aos insistentes reclamos de Michelet, que em seu prefácio, de 1869, à Histoire de France, queixava-se do desinteresse de historiadores por "tantas circunstâncias 
físicas e fisiológicas". A história biológica, mais do que aquela do corpo, decolava. Em 1970, os Annales E.S.C. dedicam-the um número, em que se discutem todas as perspectivas possíveis de tal empreitada. Um livro inesquecível, La logique du vivant, escrito por um biólogo feito historiador, François Jacob, jogava água no moinho da interdisciplinaridade. Marcel Mauss publicava, por seu turno, um artigo sobre as técnicas do corpo, cujo conhecimento em perspectiva histórica - frisava ele - deveria ser decisivo para a caracterização de sociedades e civilizações. Jacques Le Goff sublinhava, ainda, que a história da indumentária deveria fornecer ao historiador ocasião para um belo diálogo entre a imobilidade e a mudança (Le Goff 1977: 344).

A enologia ensinou o historiador a debruçar-se sobre uma documentação diferente daquela a que estava acostumado; muito além do documento escrito, passou a examinar imagens, relatos orais, objetos materiais. Novas descobertas caminharam radiosas, lado a lado com novos e soturnos problemas $^{2}$. $\bigcirc$ corpo, por certo, entrara em cena, mas como coadiuvante. Não era ainda o ator principal.

Deitando na cama...

Na segunda metade dos anos 70, e depois, ao longo da década de 80, acumularam-se trabalhos e pesquisas sobre esses imperativos tão profundamente inscritos em nossa cultura quanto comer e beber: o amor e a sexualidade. Da Antiguidade à contemporaneidade, os usos do corpo e os sentimentos que este suscitava ilustraram os trabalhos dos mais renomados historiadores. Alguns, mais solertes, estavam atentos para as armadilhas do assunto. Georges Duby, por exemplo, lembrava que, embora as maneiras de amar não fossem mais o que eram antes, e as relações entre o masculino e o feminino tenham sofrido severas transformações, as marcas explícitas deixadas pelo amor e pela sexualidade nas sociedades do passado eram bastante tênues.

Era difícil interpretar esses raros vestígios, dando conta dos lentos movimentos que apenas adivinhamos ao trabalhar a história de uma formação moral e sexual da qual só conhecemos a casca e que, de tempos em tempos, muda de pele (Duby 1984: 3). Paul Veyne dizia, simplesmente, que tais fenômenos de transformação corriam sérios riscos de manter-se indecifrados; estava convencido de que seria excessivamente simplista procurar explicações, ontem ou hoje, nos fluxos e refluxos do cristianismo (Duby 1984: 47).

Apesar das críticas, a historiografia abraçou com volúpia a possiblidade de estudar a imposição de uma nova ética sexual fundada, a partir da ldade Média, na recusa do prazer. E mais, estudou o casamento e a procriação, a medicina e suas relações com a sexualidade, as doenças sexualmente transmissíveis, os pecados da carne, a dor e o medo frente à gravidez e ao parto, o espectro da masturbação. Os documentos processuais, civis ou religiosos, davam voz a milhares de antepassados, cujas narrativas permitiam ao historiador olhar pelo buraco da fechadura da História para ver como se davam os embates entre os corpos, acompanhar seus gestos, observar seus gozos e dores. Botins arqueológicos, imagens, pintadas ou esculpidas e a literatura de época permitiram também conhecer a desinibição de culturas não cristãs. Jean Bottéro (1979, 28-42)
2. Vejam-se, por exemplo, os debates que racharam a historiografia em torno do problema de cultura letrada versus cultura popular. 
3. Ver a bibliografia do que se convencionou chamar de Historiografia da contravenção, ou seja, os trabalhos de Ronaldo Vainfas, Luis Mott, Lana Gama Lima, Fernando Londoño, Renato Venâncio, Magali Enge1, Raquel Sohiet, Luciano Figueiredo e os meus mesmos. debruçou-se com sensibilidade sobre textos mesopotâmicos, revelando como se "acordavam os corações" (metáfora transparente para o orgasmo), entre assírios e babilônios. A Epopéia de Gilgamesh guiou-o por entre as alcovas onde, precedendo os atos, rezavam-se preces para o bom sucesso do coito: "Excita-te como um cervo! Faça-me amor pois sou ardente! Doze vezes como o macho da perdiz". Paul Veyne estudou o aborto e a homossexualidade na Roma antiga, e sobre o casamento avançou a hipótese de que a moral do paganismo não seja muito diferente da moral do cristianismo. Não se deve opô-las, adverte o historiador francês, pois as verdadeiras clivagens ocorrem em outro lugar: entre uma moral dos deveres matrimoniais de cunho puritano e uma moral interiorizada pelo casal, através de vários constrangimentos (Veyne 1984: 51). Na sequência, Peter Brown (1988) abordou as práticas e as doutrinas de renúncia ao sexo - a continência, a virgindade, o celibato - que se desenvolveram nos círculos cristãos do século I d.C. O cristianismo transformara por completo o estatuto do desejo e do corpo, que passou a ser visto, então, como carne decaída e derrotada. As primeiras populações cristianizadas procuravam fugir, como o diabo da cruz, do modelo de pecado emblematizado por Adão e Eva; sua aspiração era o ideal de carne ascética vivenciado por Cristo e Maria, ideal de transcendência e negação do corpo. Jacques le Goff discutiu com maestria, que influenciou vários autores brasileiros ${ }^{3}$, a "recusa do prazer" na sociedade ocidental. O cristianismo dera ao mundo europeu uma justificação trancendente, fundamentada, simultaneamente, na teologia e na Bíblia (interpretação do Gênesis e do pecado original, ensinamentos de São Paulo e dos pais fundadores da Igreja). Mas ele também transformou uma tendência minoritária em comportamento "normal" da maioria, pelo menos nas classes dominantes, aristocráticas e urbanas, e forneceu aos novos comportamentos um novo enquadramento conceitual (vocabulário, definições, classificações, oposições) e um controle social e ideológico rigoroso, exercido pela lgreja e pelo poder laico a seu serviço. Ele oferecia o retrato de uma sociedade exemplar realizando sob sua forma ideal um novo modelo sexual: o monaquismo. A ldade Média perseguiu de forma muito objetiva os pecados da carne, encerrando-os numa rede cada vez mais apertada de definições, sanções e interditos. Para a correção de tantos erros, os clérigos (na sua maioria monges irlandeses, extremistas do ascetismol redigiram penitenciais e manuais de confissão recheados de pecados e penitências: "Com tua esposa ou com outra deitaste-te por trás, à maneira dos cães? Se o fizeste, farás penitência dez dias a pão e água", decretava, no século XII, Buchard de Worms. Os pecados da carne têm aí um lugar exorbitante, proporcional aos fantasmas e ideais dos militantes monásticos. Desprezo do mundo, humilhação da carne, o modelo ascético pesou fortemente sobre mores e mentalidades no Ocidente.

O corpo, personagem secundário destas tantas Histórias (pois estudava-se aí, a sexualidadel fez sua entrada na ldade Moderna pelas rigorosas mãos, e pesquisas, de Jean-Louis Flandrin. Em Le sexe et/'Occident (1988) o autor demonstra que uma "dupla moral" passa a ser vivida pelas populações do ocidente cristão, sobretudo depois do Concílio de Trento (1545), momento em que a lgreja, de forma severa e minuciosa, passa a regular o uso dos prazeres dentro do matrimônio. Condutas sexuais matrimoniais e extraconjugais começam a diferenciar-se; as primeiras, marcadas por estritas prescrições quanto ao prazer sexual e um feroz 
incentivo da exclusiva procriação. As segundas, experimentando técnicas contraceptivas (o coito interrompido, por exemplo) e uma crescente erotização. Valendo-se de fontes seriais como as atas de batismo, o historiador indagava se o controle exercido pela lgreja teria marcado a vida sexual dos casais casados, submetendo a sexualidade a um ritmo cujas consequências múltiplas seriam detectadas na demografia, nas relações entre sexos, nas mentalidades. Afinal, eram esses tempos em que confessores rastreavam práticas por meio de perguntas ao penitente, elaborando, graças a esse interrogatório, um calendário do que era considerado "contra a natureza": "Uniste-te à tua esposa no tempo das regras? Se o fizeste, farás penitência dez dias a pão e água... Deitaste-te com tua esposa no dia do Senhor? Deves fazer penitência quatro dias a pão e água... Deves conservar a castidade vinte dias antes do Natal e todos os domingos fixados pela lei...". Essa minuciosa análise o levou a concluir que no século VIII, por exemplo, os casais só poderiam se unir durante 91 a 93 dias por ano, sem contar os períodos ditos de "impureza da mulher" (regras, gravidez, pós parto). Em crítica à documentação que utilizara, Flandrin (1983) crê mais plausivel a continência durante os fins de semana, prática que elevaria o tempo livre da sexualidade conjugal a 184 ou 185 dias por ano. Ele observa, igualmente, um rearranjo no tempo livre da continência. $O$ total dos interditos continua mais ou menos o mesmo, mas a repartição muda: ao longo período das três quaresmas anuais sucede uma fragmentação de pequenas épocas de jejum, de abstinência e de continência.

Aos textos de Flandrin somaram-se outros. Os anos 70 e 80 foram prolíficos: John Boswell (1980), J. Bugge (1975), J.T. Noonan (1969), Aline Rousselle (1983), Jacques Solé (1976) (para ficar nos mais visitados pela historiografia brasileiral percorreram os caminhos e descaminhos da homossexualidade, da virgindade, da contracepção, do adestramento do desejo, do pudor. Seu interesse comum, se podemos simplificar delicadamente a importância destes trabalhos, era o de estudar comportamentos e práticas. Debruçados sobre textos normativos, narrativas e imagens que propunham normas de conduta, ajudaram a deixar em pedaços o véu que cobria a cultura ocidental.

Personagem secundário, o corpo ainda não era o centro da metáfora, o ponto de fusão entre o real e o imaginário. Sobre seus odores, formas, gestos e ruídos não se estabelecera, ainda, um discurso de crenças ou medos. O problema não era a falta de fontes documentais, mas sim, as perguntas que se colocavam às fontes. Neste momento, os historiadores preocupavam-se mais em questionar as relações entre a vigilância moral e a articulação do desejo, a infração e a repressão, os atos e a culpa. Os autores, direta ou indiretamente, tinham também um débito para com uma tese sistêmica que reforçava suas perguntas iniciais à documentação. A tese, fundada por Norbert Elias num livro inspirador, Uber den Prozess der Zivilisation (a primeira edição é de 1939), postula uma hipótese geral sobre a evolução dos comportamentos, e em particular das relações com o corpo, na civilização européia. $O$ notável sociólogo dos mores estudou as diferentes maneiras através das quais os homens comiam, dormiam, se assoavam, dissimulavam suas secreçōes ou tinham relações sexuais. Sua habilidade consistiu em ligar os fatos mais prosaicos do cotidiano à evolução da estrutura social do Ancien Régime. A partir do século XVI, um processo civilizatório impôs, primeiro às classes dirigentes, depois, progressivamente, ao conjunto da sociedade, por 
meio de modelos educativos (manuais de confessores, tratados de civilidade) uma atitude de pudor e autodisciplina em relação às funções fisiológicas e de desconfiança em relação aos contactos físicos. A ocultação e o distanciamento entre os corpos deveriam traduzir, nas condutas individuais, a pressão organizadora, logo modernizadora, que os Estados burocráticos, recentemente constituídos, exerciam na sociedade: a separação em classes de meninos e meninas, o confinamento dos doentes, pobres e desviantes, o declínio das solidariedades locais pertenceriam ao mesmo movimento global, difuso e largamente inconsciente, de remodelagem do corpo social. Como bem sintetiza André Burguière 11988, 152), nascia, então, um claro paralelismo entre a privatização do eu, a reorganização do corpo e apropriação privada dos meios de produção. Esta obra, fundamental em si, favorecia os historiadores que procuravam articular suas pesquisas individuais a uma explicação abrangente, que desse conta dos fenômenos sociais e econômicos. Ela embasava a articulação simultânea entre história episódica, conjunturas e estruturas, na qual se captavam as pulsações dos fenômenos culturais relativos ao corpo, no interior de diferentes tempos históricos.

A demografia histórica, método que se expandira ao longo da década de 70, ajudava ainda a iluminar os efeitos de certas políticas do corpo nos comportamentos demográficos (Lebrun 1975; Bardeł 1983; Dupâquier 1982). Os cuidados matemáticos com que eram avaliadas taxas de natalidade, fecundidade, nupcialidade, morbidez e mortalidade aparelhavam os historiadores para interpretar as atitudes diante da vida e da morte. Nestes cerrados cálculos, o corpo era um número ou um diagnóstico, embora servisse para interpretar o mistério dos comportamentos coletivos.

O imenso sucesso e a profusão de textos publicados em torno destes temas não deram lugar a uma reflexão crítica sobre o papel do corpo na história. As grandes divergências e polêmicas ficaram por conta da maior ou menor ação da lgreja na chamada "cristianização" ou normatização dos usos do corpo e da sexualidade. Debitando-o ao impacto do "monaquismo" entre as elites do século XIII ou à laicização das sociedades desenvolvidas durante o século XVIII, historiadores seguiam debatendo assuntos que consideravam fundamentais para pensar o homem na atualidade: a liberação sexual, o fim do casamento como instituição, a fisionomia da família contemporânea, o amor, etc. Tais objetos consagraram os historiadores europeus cujas obras passaram a frequentar as listas de best-sellers (Le Roy Ladurie 1975) mas silenciavam o outro: o corpo, ele mesmo.

O corpo, modo de usar

Na década de 80, o diálogo da História com a Antropologia aguçouse. As razões que levaram ao aumento da intimidade entre essas "duas amigas", como as chamou Lilia Schwarcz (1994: 69), escoravam-se na busca de lógicas culturais diversas, diluidoras das fronteiras entre o simbólico, a imaginação e a objetividade, para explicar os fenômenos históricos. Os historiadores perceberam que o imaginário e o simbólico preenchiam o campo perceptivo e que, num jogo de sutis sentidos, emprenhavam as palavras e contaminavam os gestos cotidianos passiveis de interpretação. $O$ corpo passa, pois, a interessar ao historiador como espaço constitutivo de laços sociais. Seus atos, gestos e práticas são elementos de 
uma cultura, retratam sistemas de valores específicos, organizam um modo de vida.

Mais além, o universo interno e externo do corpo aprisionado pelas palavras, desenrola-se aos olhos do historiador cómo um afresco orgânico. Cada orgão ou função, cada-tecido ou secreção abre-se em impressionante reconstituição fisiológica: Por meio das palavras, o corpo se constrói e desconstrói infatigavelmente, num complexo jogo de equivalências e correspondências, de transbordamentos $e$ de nivelamentos. É nesta linha fronteiriça que as imagens da vida interior/exterior do corpo ganham sentido.

Primeiramente, nas fantasias dos arranjos entre dois niveis, um feito de líquidos e vísceras; outro, de sensações, de desejos e de sentimentos. Segundo, na precariedade dos arranjos entre o interno e o externo no qual se evidenciam as relações com o campo social (médicas, estéticas, religiosas). Tais construções permitem um olhar sobre um corpo que está simultaneamente inteiro e desconjuntado, firme e flutuante, possuindo as virtudes de assentá-lo numa representação na qual se aliam as propriedades contraditórias de identidade e fragmentação (Durif 1992: 71-76).

Ao final da década, algumas coletâneas chamavam atenção para o diálogo com a antropologia e convidavam a uma sondagem em diferentes compartimentos históricos.

Uma das primeiras intitula-se Le corps à la Renaissance (Ceard et al., 1990) e reúne trabahthos de especialistas em estudos sobre o Humanismo. Uma noção básica conduz o teor dos ensaios: a idéia de corpo, tout-court, é mais significativa em nossa época do que no período enfocado. Não se quer dizer com isso que o problema do corpo não existiu durante o Renascimento, momento por excelência de tantos tratados de medicina, de dança e de cosmética, sem contar as inúmeras representações do ser humano, cujas particularidades físicas nunca foram exploradas de forma tão convincente. Mas o possante élan que conduziu a cultura ocidental na direção de uma apreensão mais completa e jubilosa do ser físico passava, automaticamente, por considerações sobre a alma: ser psíquico mais importante, mais sério, mais nobre do que sua contrapartida, ou melhor, seu invólucro corporal.

O importante a sublinhar é que, desta feita, é o corpo na sua realidade corporal (se assim o podemos dizer) e não enquanto determinação conceitual que aparece: corpo e moda vestimentar nos quadros flamengos e italianos do século $X V$; o corpo e a casa, as possíveis relações entre Francisco l e Henrique ll com os espaços do Château Royal de Saint-Germain-en-Laye; o ideal de beleza feminina nos brasões poéticos de Clement Marote outros; o conceito de beleza masculina durante o Renascimento; as funções e significações da roupa para além da preservação material do corpo; as possíveis e variadas interpretações das Dame au bain de François Clovet; o imaginário sobre o corpo e a violência nos tempos das guerras religiosas; o corpo do supliciado e as técnicas anatômicas de dissecção; o corpo-armadilha da feiticeira; o corpo em agonia, socializado pelos manuais de bem-morrer, comparado à agonia dos mártires e dos condenados; as relíquias corporais; a representação do corpo de Deus na arte do século XV; o uso espiritual e teológico dos cinco sentidos do corpo; a consciência do corpo na poesia inglesa, de Spencer a Milton; o lugar do corpo na iconografia inglesa; a teatralidade 
do corpo e a dança; o corpo e a música; a nominação do corpo na linguagem do século XVI; a semiótica gestual no Renascimento; os cuidados com o corpo inspirados pelas viagens à Terra Santa; exercícios, saúde e ginástica médica; a arte da caça como formadora do corpo do rei; o cavalo como instrumento dos movimentos corporais; o manejo da espada e a pedagogia do corpo; a anatomia do olho, de Vesálio a Kepler; a questão da beleza nos corpos anatomizados por Vesálio; o amor e o corpo.

A ambição da coletânea é modesta; longe de pretender dizer tudo sobre o tema do corpo no Renascimento, ou de querer fazer um balanço de domínios já bem explorados, os autores apoiaram-se em disciplinas que dominam, para aclarar de maneira mais fina, o estado atual das "divergências" sobre a questão. Nada de sínteses, que seriam consideradas prematuras, uma vez que coexistem inúmeros pontos de vista sobre o tema. Explorando, sobretudo, o domínio do imaginário e do simbólico, demonstram que o Renascimento renovou a consciência que os indivíduos tinham então do corpo, os meios de observá-lo e de modificá-lo. E eles terminam por revelar, com grande talento, uma época em que o corpo foi tão amado quanto detestado.

Em 1989, Michel Feher, Ramona Nadaff e Nadia Tazzi editam, em três volumes, o belissimo Fragments for a History of the human body (1989). A perspectiva de uma "outra" coletânea sublinha o aspecto experimental dos estudos sobre o corpo. A noção mesma de "fragmentos", posta no título, implica a negação do caráter de síntese da obra. Nela, sequer existe a pretensão de definir o que seja história do corpo. Os temas e objetos tratados apontam para a extensão do campo a ser explorado e introduzem as variadas técnicas de abordagem das pesquisas aí realizadas. A tônica dos artigos é a interdisciplinaridade. História, antropologia e filosofia cruzam-se, dando mais musculatura ao conjunto dos textos do que qualquer mirada geral ou do que qualquer esquema previamente delimitado de assuntos.

No primeiro volume, a abordagem é verticalizada no domínio da relação do corpo com o divino, com o bestial e com as máquinas que o imitam ou simulam. O segundo cobre as várias junções entre o "fora" e o "dentro" do corpo: estudam-se as manifestações - ou a produção - da alma e a expressão das emoções através das atitudes corporais e, em outro nível, as especulações inspiradas pela sinestesia, a dor e a morte. A terceira abordagem traz à tona a oposição clássica entre organismo e função, mostrando como certo orgão ou substância corporal podem ser usados para justificar ou desafiar as funções sociais e, reciprocamente, como certas funçôes políticas e sociais empurram os corpos dos individuos a preencher funçães de um corpo maior, o social ou aquele do universo como um todo.

Impossivel resumir a riqueza dos textos que inúmeros especialistas como Jacques Le Goff, Thomas W. Laqueur, Giulia Sissa, Françoise Héritier-Augé, Aline Rousselle, Louis Marin, Jean-Pierre Vernant, Piero Camporesi, Nicole Loraux, Jean-Claude Schmitt, Georges Vigarello, Mario Perniola, entre outros, escreveram. Mas neles, o diálogo entre história e antropologia evidencia-se. Ele é conduzido pelas relações entre diacronia e sincronia, por aquelas entre natureza e sobrenatural e aborda as correspondências cósmicas da vida coletiva, as diferenças de comportamento ligadas ao meio físico, ao environment. Todos os signos de 
experiência para os quais concorre o corpo nas suas práticas cotidianas ou naturais, até a análise dos mecanismos mentais, de postulados aprisionados em elaborações doutrinárias, são campo de estudos para esses historiadores. A abordagem antropológica da maior parte dos textos consiste numa leitura minuciosa de discursos e de símbolos; primeiramente, reúnem-se, de forma paciente, os elementos que estabeleceram os discursos; depois, busca-se a sua coerência e compreensão até chegar, sem indução precipitada ou mecanização banalizante, ao estudo dos símbolos. Por trás destes, analisam-se os gestos e atos de que são compostos. A opção diacrônica leva a analisátos contra o pano de fundo do trabalho profundo e misterioso dos comportamentos coletivos: episódios históricos variados, a constituição de um vocabulário ou de um "discurso" que lhes dê forma, mutações, pulsões abortadas, são tantos os elementos de interpretação que mais nos fazem pensar em vasos comunicantes entre a fixação histórica de tais símbolos e a sua lenta e muda gestação.

Renaissance bodies: the human figure in English culture c. 1540-1660, editado por Lucy Gent e Nigel Llewelyn (1990) foi, talvez, a primeira coletânea publicada na Inglaterra sobre a história do corpo. Sua proposta é a de introduzir as várias maneiras pelas quais a figura humana era representada na arte e na literatura da sociedade inglesa do Renascimento. Os temas visitados variam entre a arte erudita e a cultura "popular", de retratos reais de Isabel I a polêmicos impressos ridicularizando o fanatismo. religioso, incluindo, ainda, o estudo de miniaturas, modos e maneiras, anatomia, drama e arquitetura. Os autores, historiadores da arte e críticos literários refletem a diversidade de interpretações sobre o conceito mesmo de body e de figure: o segundo sugere contornos e representação, as formas do corpo, "un unbodied human form"; a palavra ainda carrega um sentido de abstração e distância como se a forma humana fosse vista, externamente, por alguém. Body, por contraste, sugere o solidamente nãorepresentado fato da existência, uma materialidade inarticulada em si. É a substância muda da qual figure representa a sombra mais expressiva e nervosa. Enquanto associa-se figure ao que é abstração ou matemática, body gravita em torno do que é morte e anatomia. Os ensaios chamam a atenção para o fato de que a despeito do corpo ser a paisagem mais familiar dos indivíduos, não é fácil ler seus sentidos.

Apenas para demonstrar a descentralização dos debates e estudos sobre o corpo, vale, ainda, lembrar a coletânea publicada sobre o corpo na sociedade espanhola dos séculos XVI e XV|I (1988). Como se representava o corpo na Espanha do século de Ouro? Que importância the davam? Que cuidados the eram ministrados? Quatro vertentes de trabalhos foram organizadas: o corpo vivido no cotidiano, o corpo em crise, o corpo em festa, o controle social do corpo. Na primeira parte, a mais longa, aliás, D. Gelis mostra que no século de Ouro duas concepcões se opunham: uma rural, na qual o corpo era visto como uma parte do corpo coletivo, e outra, aquela da lgreja, para quem o corpo era fonte de corrupção. Com a descoberta do Novo Mundo e o avanço da técnica, o corpo "se individualiza" e torna-se objeto de maiores cuidados. F. Delpech estudou as marcas de nascença e sua localização no corpo, reveladoras do caráter ou do destino mais ou menos prestigioso daquele que nascera marcado. Baseando-se sobre os livros de fisiognomia do século XVI, J. Raudière de la Roche 
mostra que os hábitos e as qualidades dos homens eram conhecidas pela sua semelhança entre algumas partes do corpo (estatura, cabeça, rosto) e aquelas de alguns animais. Em seu artigo consagrado ao sono, A. Milhou-Rodie expōe como, considerado um pecado associado à preguiça e à gulodice, mas também por sua semelhança com a morte, o sono foi reprimido e depois reabilitado, graças a seu aspecto benéfico, reparador dos cansaços e fadigas.

Que roupas cobriam, então, os corpos? M.C. Barbaza estudou por meio de arquivos (contratos de casamento, dotes, etc.) as peças vestimentares da camponesa, evidenciando a semiologia do código vestimentar da mulher rural da época: matérias, cores, formas revelam quer a hierarquia social, quer o estado civil da mulher (moça, viúva, etc.), ou ainda seu lugar na sociedade. J. Allard debruçou-se sobre as regras alimentares prescritas pelos médicos, que então recomendavam uma certa sobriedade na alimentação, e que indicavam a quantidade, a qualidade e a ordem na qual devia ser ingerida. Enfim, M.C. Simon Palmer sublinha tudo o que dizia respeito ao corpo do Rei e das pessoas reais como parte de atenções particulares: comida rica e copiosa, ritual de toilette minuciosamente ditado, etc.

Depois das vivências cotidianas do corpo, uma segunda parte aborda o corpo do ângulo da doença e do sofrimento. R. Garcia Cárcel enfatiza a questão do corpo eclesiástico, que criticava a atenção exagerada dada à estética do corpo (vestimentas, maquilagem, etc.), lembrando que esse, quando morre, termina como poeira. Esta obcessiva referência à morte conduzia a soluções supersticiosas. As numerosas vagas de epidemias da época, sobretudo a peste, não podiam deixar de ser evocadas. Foi do que se encarregou B. Vincent. Para contrabalançar a insuficiência de médicos e confessores face à doença, organizavam-se procissões e rogações para conjurar o mal, ou realizavam-se Ações de Graças para agradecer a cura ou o fim das epidemias. São os corpos sofridos de doentes, loucos e pobres, encerrados em hospitais em Toledo que interessaram a R. Saez, que estudou o funcionamento e as farmacopéias destes estabelecimentos. Mas o corpo era também vítima de violência, violência onipresente na Espanha de Ouro. R. Carasco busca suas causas, indica as armas, localiza os locais do crime, o momento e a condição do agressor, bem como as motivações desta violência.

Corpos reclusos, corpos supliciados e A. Guillaume evoca as Santas Hermandades (polícia rural e tribunal ordinário de justiça) que torturava seus prisioneiros quer para fazê-los confessar, quer para castigá-los, encarregando-se até de execuções em terriveis condições. Geralmente o suplício era público e é sobre esse lado espetacular do corpo supliciado, mutilado, decepado que A. Redondo se baseia para mostrar o quanto o terror $e$ o medo são geradores de ordem. A literatura popular ou erudita ecoa, por sua vez, as dores que podem fustigar o corpo. D. de Courcelles encontrou nos goigs lorações cantadas na Catalunhal, evocações de corpos doentes, mal formados, corpos de mártires ou de santos, ungidos por milagres. Impressos em folhas volantes, os goigs, cantados pelos fiéis na igreja, traziam-thes não somente conforto, mas esperança de ganhar, pelo sofrimento, o céu. Por meio de toques impressionistas, J. Jauralde Pau demonstra, através da poesia clássica, de Garcilaso a Quevedo, a evolução do espiritual na contemplação do corporal: se as metáforas poéticas sugerem a beleza do amado, 
o corpo é igualmente visto como restos que se abandonam ao morrer. E nos sermões e na poesia popular do século XVII estudados por M.C. Garcia de Entérria, o corpo é fonte de pecados e será, consequentemente, objeto de punições (males, peste, horrores do inferno), donde toda uma ética de comportamentos para ocultáto, preservando a alma das tentações físicas.

Sylvia Roubaud abre a terceira parte consagrada ao "Corpo em festa" falando de dois traços característicos do herói de cavalaria: a beleza e a aptidão para as grandes ações. Quanto maior a beleza do cavaleiro (estatura, largura de ombros, braços e pernas bem feitos) mais chances de ser um valoroso guerrreiro. Todavia, esta beleza refletia-se nos romances de época com a mesma linguagem empregada para descrever a beleza feminina; o que resultava numa feminização de homens cuja virilidade e bravura deviam ser destacadas.

Pedro Córdoba observa que o esporte, tal como o concebemos hoje em dia, não existia na Espanha do século de Ouro. Nem a palavra existia. O que não quer dizer que não se praticassem exercícios físicos, na sua maior parte técnicas de preparação para a guerra. J.Huerta Calvo debruçou-se sobre as múltiplas facetas por meio das quais o corpo se desdobra em cena, ligadas às diferentes formas de representação: mogigangas (em que o corpo é portador de fantasias exóticas), jácaras (onde o corpo é alvo de violencias verbais), bailes (nos quais o corpo se contorce em sensualidade), entremeses (em que o corpo apresenta aspectos grotescos ou obcenos).

Como reagia o corpo social à nudez ou às atitudes provocantes, até mesmo grosseiras, evocadas acima? A última parte do livro traz elementos de resposta. No que diz respeito à nudez, $H$. Kamen sublinha o fato de que apesar de este problema ter sido abordado sob diversos aspectos (rosto descoberto, decotes, nus no teatrol, os dirigentes religiosos espanhóis foram incapazes de suprimir a nudez pública e de purgar o teatro de seu conteúdo sexual. P. Civil evoca a regulamentação e o aparetho repressivo colocado em ação na segunda metade do século XVI, no domínio da indumentária. Ocorreu, no reinado de Felipe II, uma certa uniformização da roupa de corte; tentou-se fugir dela pela utilização de excessos contra os quais travou-se uma luta sistemática. O controle social do corpo é analisado por F. Copello e I. Rada, através dos personagens antagonistas de D. Quixote e Sancho Pança. O primeiro possui uma aparência física que o impede de ser o perfeito cavaleiro, o segundo não passa de um humilde camponês. D. Quixote adestra seu corpo e é capaz de ser civil e cortês; ele tenta fazer de Sancho um homem distinto, mas esse não chega a se acomodar no interior das regras de civilidade. Corpos rudes versus corpos policiados: os autores mostram as dificuldades que tinham os protagonistas em adaptarem-se aos comportamentos ditados pelo código de seu estatuto social. Uma última comunicação, a de L. Lopez Baralt, evoca a imagem dos mouriscos na literatura. Como eram vistos e como se viam entre si? A diferença entre as duas comunidades, cristã e muçulmana não se baseava no físico, pois ambas tinham, em sua grande maioria, cabelos e olhos castanhos. Mas o curioso é que os mouriscos não se viam assim. Em sua literatura oral, não há um único moreno; todos os personagens são louros e os mouriscos não se distinguem dos cristãos - como ainda hoje soe acontecer - senão pelas roupas. Temerosos das sevícias às quais podiam ser submetidos, os mouriscos recusavam, em sua literatura, a sua identidade e viam- 
-se, não como eram, mas como gostariam de ser.

Viagem vertiginosa através de usos e costumes em torno do corpo na Espanha, o livro organizado por A. Redondo revela pistas temáticas interessantíssimas, baseadas em documentos de grande qualidade, mostrando, ainda, que apesar da influência francesa da Nouvelle Histoire, historiadores em outras plagas souberam aproveitar as contribuições da antropologia e da sociologia para tratar da fabricação cultural, a estética, a cosmética, a ergonomia, o esporte, a identidade, os hábitos corporais e toda uma infinita gama de assuntos relativos ao corpo.

A mais tônica combinação entre antropologia, história da medicina e história das cidades, foi conseguida por Richard Sennet em seu belíssimo Flesh and stone - the body and the city in western civilization (1994). "Carne e pedra" é a história das cidades contada através da experiência corporal, física, de seus habitantes: como homens e mulheres se movimentam, o que vêem e ouvem, que odores assaltam suas narinas, o que comem, como estão vestidos, quando se banham, onde fazem amor nas cidades, da antiga Atenas à moderna Nova lorque. O livro de Sennet usa os corpos como instrumento para compreender o passado e é muito mais do que um simples catálogo de sensações físicas vividas no espaço urbano. O autor entende que a civilização ocidental teve persistente dificuldade em honrar tanto a dignidade, quanto a diferença dos corpos humanos e que tais "dificuldades-corpóreas" traduziram-se na arquitetura, imiscuiram-se no traçado urbano, refletiram-se nos projetos de cidades.

Que significado teria a nudez para os antigos atenienses, quando do início da guerra do Peloponeso, no auge da glória da "pólis"? $\bigcirc$ corpo exposto e desnudo fora, por longo tempo, considerado como o emblema da auto-confiança de um povo, orgulhoso de sua cidade. Mas Sennet entende, diferentemente, que tais ideais físicos serviram como fonte para tensões entre homens e mulheres, para a formação do espaço urbano e para a prática da democracia ateniense. O segundo capítulo enfoca Roma no tempo em que o imperador Adriano completou - Pantheon. O autor explora, aí, a crença dos romanos em imagens, particularmente aquela da geometria do corpo, e de como eles traduziram esta crença num design urbano e em práticas imperiais. O corpo, a casa, o fórum, a cidade, o império: tudo se baseava num imaginário linear. A crítica arquitetônica revelou o gosto romano por uma precisa orientação espacial, espaços com octógonos bem definidos, estruturas com formas simples como o arco romano, um meio círculo, ou construções feitas a partir de volumes bem definidos. Este desejo de uma orientação correta revela uma linguagem visual na qual expressa-se a vontade, difícil e desigual, de cada cidadão ter o seu lugar reafirmado no espaço físico da cidade. O poder de ver, enxergar, usar os olhos na direção desta paisagem urbana linear e repetitiva, levou, literalmente, os romanos a esmaecer suas sensibilidades; fraqueza esta que os cristãos da época de Adriano começaram a desafiar e a explorar. Numa terceira parte, o estudo procura enfocar como as crenças cristãs esculpiram o desenho urbano na Alta ldade Média e no início do Renascimento. O sofrimento físico do Cristo na cruz permitiu aos parisienses do Medievo, pensar na erecção de espaços de piedade e caridade dentro da sua cidade. Tais espaços abrigavam-se em ruas peculiares, livres da agressão física e da violência, típicas de uma sociedade de mercado em expansão. 
Mais a frente, no início do Renascimento, cristãos europeus viam seus ideais de comunidade ameaçados pelas ordas de não-cristãos e não-europeus que eram lançados na órbita urbana economica. Estas ameaçadoras diferenças deram origem, por exemplo, à criação do Gueto veneziano em 1516. Na quarta e última parte, Sennet explora os desdobramentos do espaço urbano à luz das leituras científicas modernas sobre o corpo. A revolução começou com a publicação do De motu cordis, de Harvey, no início do século XVII, trabalho médico que alterou, radicalmente, a compreensão da circulação do sangue no corpo; esta nova imagem do corpo, visto como um sistema circulatório, inspirou no século XVIII, tentativas de livre circulação na cidade. Na Paris revolucionária, por exemplo, esta nova imagem de liberdade corpórea entrou em choque com a necessidade de espaços comunitários onde se exerceriam rituais de sociabilidade. Depois da grande explosão de violência catártica, do festival de corpos guilhotinados, os primeiros sinais de passividade apareceram. As pinturas sobre o corpo da emblemática Marianne mostram a passagem desta combativa substituta de Hércules a uma mulher pacificada.

O triunfo dos movimentos individuais na formação das grandes cidades do século XIX levou ao particular dilema, no qual hoje vivemos: o movimento individual do corpo é alavancado pela falta de respeito e consciência dos outros seres humanos? Como se dá a tensão entre uma noção de espaço individual como espaço-sacralizado e aquela outra, de espaço enquanto cena viva, na qual as pessoas expõem as suas diferenças e discordâncias. Debruçado sobre os textos de E. M. Foster, cujo cenário é a Londres oitocentista, Sennet destila idéias incriveis sobre como viver em cidades multiculturais nas quais o "não-lugar" é uma evidência maior do que o conforto ou a segurança.

Se Michel Foucault foi hábil em revelar os poderes invisíveis que controlavam e moldavam sociedades, nas quais os corpos dobravam-se e curvavam-se à vontade das instituições, Sennet revela os corpos criando as formas da vida civil e a cidade.

As curvas e linhas (metodológicas) do corpo

Hoje vivemos e pensamos as aventuras de nosso próprio corpo, pois este encontra-se valorizado por noções como saúde, erotismo, sexualidade. Por ser território de catástrofes e alegrias, de gozo jubilatório e dor tristonha, o corpo tornou-se medida do mundo. Os historiadores que se lançaram em outra aventura, aquela de contar-narrar-interpretar a história do corpo, por meio de obras sistêmicas invocam, com insistência, essa articulação com as demandas contemporâneas. "A importância dada ao corpo, no nosso tempo, contrapõe-se ao ofuscamento a que estava submetido no passado [...] os novos valores de beleza, felicidade ou juventude identificaram-se com um corpo que se transforma em objeto de cuidados e desassossegos. O projeto de libertação do corpo está presente em cada momento, exprimindo-se numa dinâmica multifacetada e atingindo a imensa teia de relações sociais", explica Jorge Crespo em sua História do Corpo (1990: 7).

Indo mais além, Barbara Maria Stafford (1 991) sublinha que a revolução técnica e intelectual foi capaz de iluminar os corpos de fora para dentro, ensinando-nos a ver o invisivel. Estratégias visuais e teorias postas em marcha no século XVIII, 
momento em que metáforas para pensar o que estava "out of sight" eram desenvolvidas, foram substituídas por técnicas universalizantes de visualização, componentes corriqueiros da existência moderna: "Think of the miraculous new medical imaging technologies (CT, PET and MRI scanners) that noninvasively open windows into secret depths of the body and of the brain. Think, too, of electronic imagery that inverts the very notion of substantial labor. In today's workplace, computer monitors 'disembody' information on into ghostly green and amber apparitions that float before the eyes. Think of our legal system in wich courtroom exhibits anatomical models, and even films of the day in the life of an accident victim have metamorphosed the concept of 'eyewitness account' ".

O diálogo constante do historiador com outros cientistas sociais faz de seu trabalho um lugar de reflexão sem equivalente sobre o tema do corpo, pois não linear, não coeso. As lentes da antropologia, da sociologia, da arte e literatura ajudaram a revelar um objeto histórico plural e heterogêneo, pois, como explica Denise Bernuzzi de Sant'Anna (1995: 13), "estudar o corpo implica, assim, trabalhar segundo uma perspectiva genealógica, voltada à apreensão das condições de possibilidade que fazem emergir, em cada época, as relações e as oposições entre os corpos, suas designações e suas especificidades".

As curvas e linhas do corpo são por sua vez esculpidas pela lenta respiração histórica: "a história do corpo deve ser perspectivada na 'longa duração' e confrontada com a multiplicidade de tempos, espaços e de técnicas elaboradas a partir de atitudes mentais que não é fácil delimitar", adverte Jorge Crespo (1990: 572). Mesma longa duração braudeliana invocada por Thomas Laqueur para demonstrar que o Ocidente, desde suas origens, jamais cessou de interrogar-se sobre a diferença e a singularidade dos sexos.

O corpo vivo e vivido, experimentado e experiente, transformouse, assim, em objeto: um objeto capturável e unificado. Objeto cuja extensão implica, também, a sua limitação; o corpo é finito, móvel e irretocável. Mas na sua aparente identidade, imobilidade e finitude ele é processo, resultado de gestões sociais e culturais, fruto de representações e de imaginário, agente de movimentos, fragmento de desordens. Na perspectiva histórica, a distinção entre vivos e mortos desapareceu pois, nas mãos do historiador, o corpo resiste às fadigas e às intempéries. $O$ corpo polissêmico que o historiador resgata do documento é um corpo de plenitude, ignorante de necessidades e carências, esplêndido, pronto a responder às suas questões.

Quando o historiador fala do, e pelo passado, ele compara, ao menos implicitamente, este passado ao seu presente, aquela cultura à sua, para detectar o papel e a ação dos indivíduos e seus corpos, avaliando, no tempo, transformações e permanências. Face a uma outra sociedade que não a sua, historiadores, como etnólogos, espantam-se com a descoberta de sistemas simbólicos rigorosos e ancilares a respeito dos usos do corpo. Estudos recentes demonstram a vitalidade destes códigos, ainda hoje, em nossa vida cotidiana: especialistas em "proxêmica", como E.T. Hall, demonstram quais espaços simbólicos o homem cria com o seu corpo. A ciência do movimento corporal, a "kinésica" de R.L. Birdwhistell, analisa todos os códigos implícitos na comunicação não verbal. Espectadores de uma cultura mediática, bem sabemos que as imagens vivas da televisão só fazem reforçar a importância do corpo. O bom de inquirir o passado, é que esse nos 
permite reconhecer a linguagem de nosso próprio corpo, recuperando gestos que se repetem a séculos. A Cortesã apaixonada de Nicolas de Larmessin (figura 1) ou os amantes, pintados por Abraham Bosse (figura 2), por exemplo, trocam carícias que nos são familiares. A Eva de Lucas Cranach (figura 3 ) não teria ganhado peso depois da introdução do açúcar americano na Europa? Comparêmo-la, por exemplo, às gorduchas rosadas de Rubens e às bonecas de silicone produzidas, hoje, pelos cirurgiões plásticos. A caveira da vanitas barroca lfigura 4) não migrou para o trash-movie?

Os corpos são, por natureza, efêmeros. Eis porque a prêsa do historiador consiste, em grande parte, em representações que são, também, interpretações dadas pela cultura que as produziu. Tais representações encontramos, primeiramente nos textos. Estes dissecam, descrevem, cantam, maltratam os corpos. Ou então, explicam as suas intencionalidades. Outros ainda testemunham uma reflexão mais abstrata sobre o corpo, aplicando-lhe um julgamento estético ou moral, ou precisando sua significação dentro da cultura de um determinado tempo. Em todos os casos, importa ao historiador dar conta das mediações que se interpõem entre as palavras que ele lê e os usos dos corpos. Qual é a utensilagem mental do narrador? Que objetivos perseguia com o seu texto? Que vocabulário empregou para tratar do corpo?

De outro lado, podemos recorrer às imagens e à cultura material: Vaste programmel Nas imagens, da pré-história aos nossos dias, encontramos representações sobre o corpo. E a imagem, contrariamente ao texto, não pode se contentar em evocar, sem mostrar. Os objetos da cultura material, ou seus restos, permitem as mesmas inquirições. Qual a função de determinada imagem ou objeto numa dada sociedade? Qual o valor lógico próprio de uma imagem ou de um objeto?

A história do corpo é, hoje, uma evidência. Trabalhos, colóquios, livros dão conta do interesse em explorar tal objeto. A matriz francesa, mais ancorada nas "mentalidades", depois de ter inspirado vários ensaios e teses, cedeu lugar a enfoques nos quais a antropologia, a história da arte e a história da cultura material dialogam mais agilmente com as fontes documentais. Procurei tratar aqui de uma pontinha do "iceberiano"-resultado destas investigações. As razões que inspiram esta abordagem, esse recorte, encontram-se, insisto, na atualidade: a obcessão eugênica, a crise do Estado enfraquecido na sua missão de policiar as condutas humanas, a emergência de novos e furiosos vírus. Ora, enquanto tais questões estiverem chamando a atenção do historiador, ele se sentirá impulsionado a conhecê-las através da dimensão de seu trabalho. Quanto às fontes a interrogar, elas são inesgotáveis como já ficou demonstrado nos exemplos dados.

Mas se não houvesse mais quaisquer bons motivos para fazer a história do corpo, encontraríamos um nas divagações de Fedro, um dos mais sensíveis personagens de Paul Valéry (1996: 34):

"O corpo é um instrumento admirável, pelo qual me asseguro de que os viventes, tendoo cada qual a seu serviço, dele não dispõem em plenitude; extraem apenas prazer, dor, e os atos indispensáveis para viver. Ora confundem-se com ele, ora distraem-se por algum tempo de sua existência; ora animais, ora puros espíritos, ignoram os vínculos universais que possuem. Graças, no entanto, à prodigiosa substância de que são feitos, participam do que vêem e do que apalpam; são pedras, árvores, trocam contatos e 
4. Agradeço ao Prof. Joaquim Manoel Guedes (FAU/USP) a amável indicação deste texto. intimidade com a matéria que os engloba; tocam, são tocados; pesam e sustentam pesos, movem-se e transportam suas virtudes e seus vícios; e quando entram em devaneio, ou em sono indefinido, reproduzem a natureza das águas, fazem-se areias e nuvens..." 4 .

É este extraordinário mimetismo, a matéria do corpo ele mesmo e, simultaneamente, a matéria do poeta e aquela do historiador.

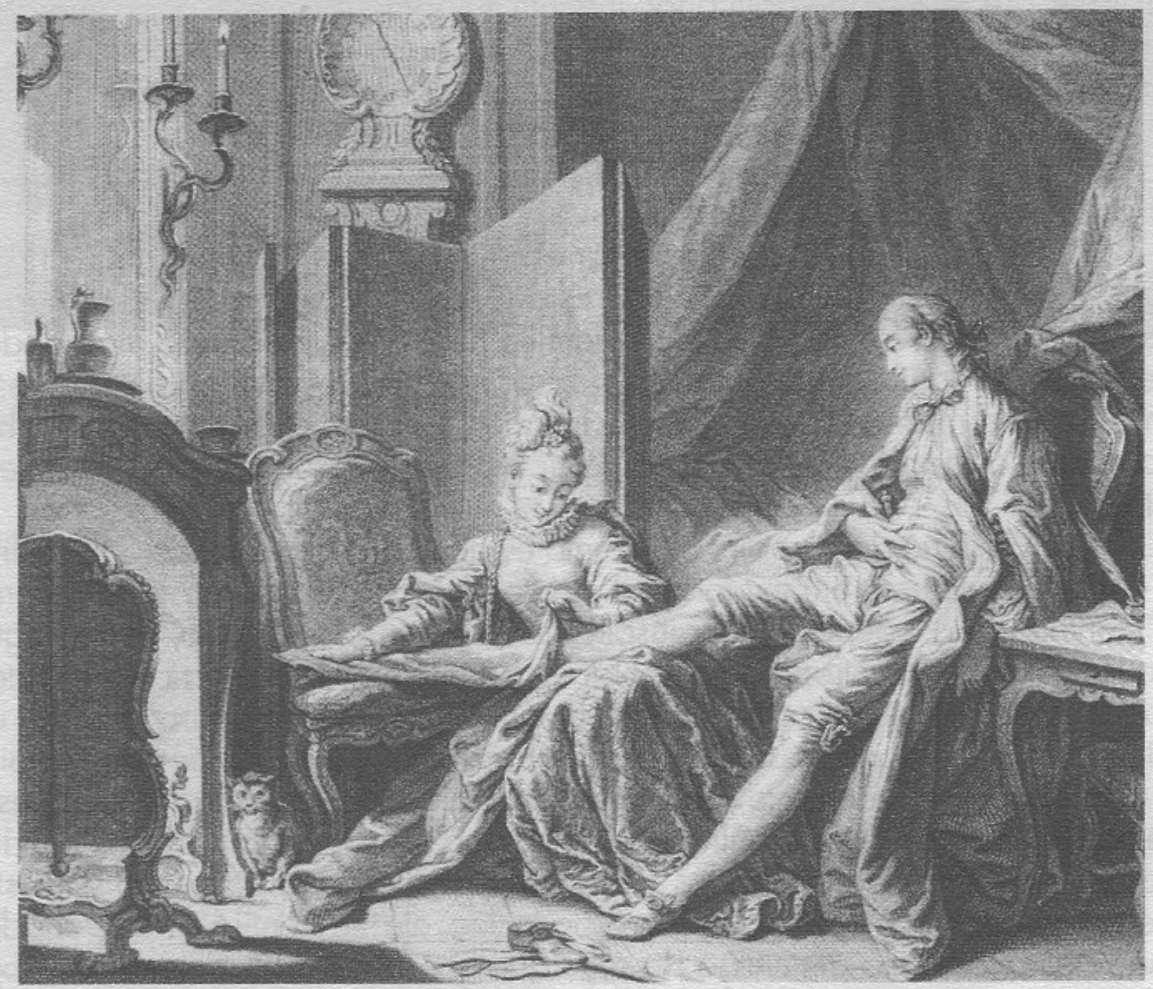

Fig. I la Courtisanne amoureuse. Nicolas de Larmessin IV. Gravura em talho doce, a partir de François Boucher, para a "série de Larmessin", c. 1740.

Bibliothèque Nationale de France 


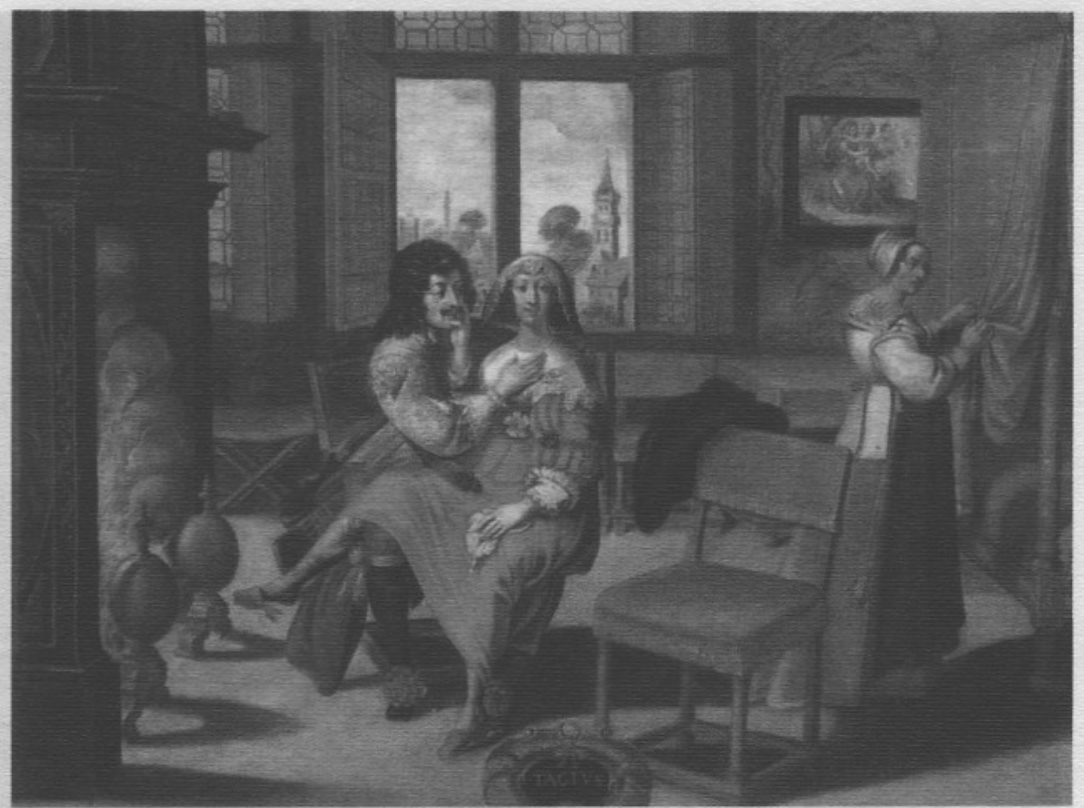

Fig. 2 Le toucher. Anônimo (França, século XVII), a partir de Abraham Bosse (1602-1676).

Musée de Beaux-Arts, Tours

Fig. 3 Adam und Eva. Lucas Cranach (1472-1553). Madeira, $47,2 \times 35,3 \mathrm{~cm}$. Alte Pinakothek, Munique

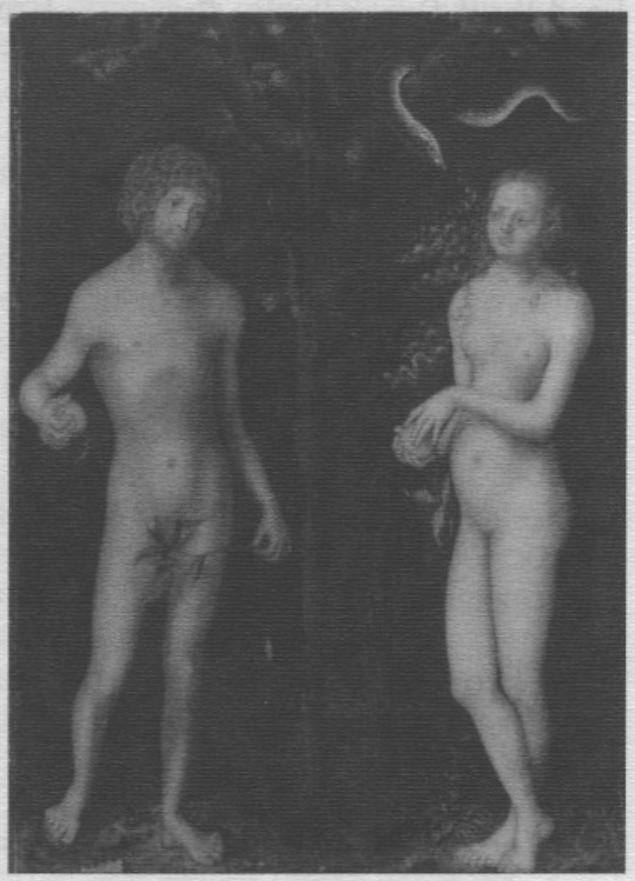




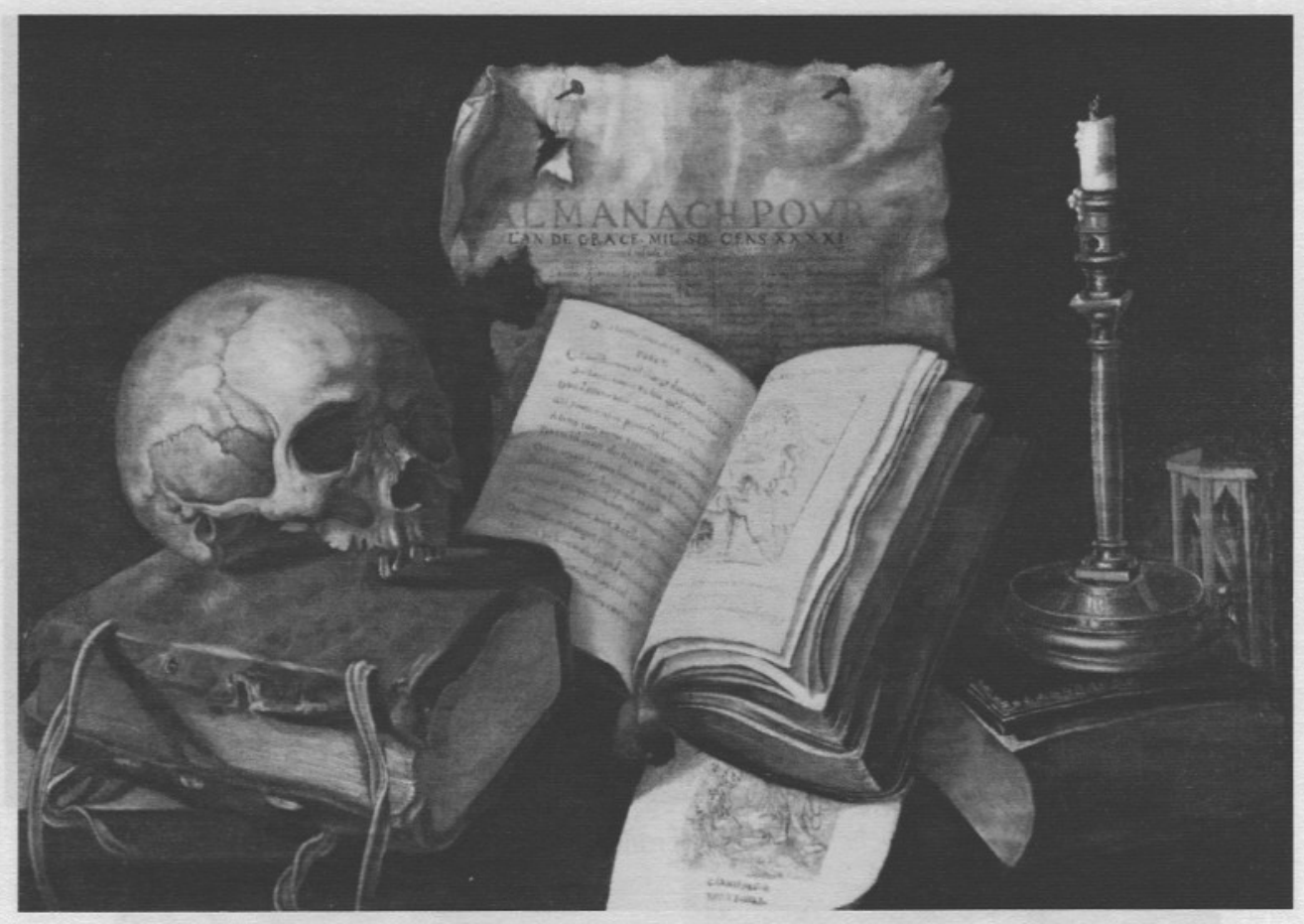

Fig. 4 Vanité. Damien Lhomme (Troyes, século XVIII). Clichê A. Allemand. Musée de Beaux-Arts, Troyes 


\title{
RESUMOS / ABSTRACTS
}

\author{
Dossiê: história do corpo
}

\section{Mary Lucy Murray Del Priore}

Este artigo; apresentado como texto-base para a seção "Debates", é uma seleção de abordagens sobre as formas pelas quais o corpo humano tem sido representado na História. Os assuntos discutidos vão da Antropologia à Literatura e incluem a Nova História Social, a História da Medicina e a História da Arte. Embora não se trate nem de um balanço exaustivo, nem de um estudo sistemático de uma porção compacta da História do corpo, pocurou-se refletir interdisciplinarmente a multiplicidade de pontos de vista e assinalar as vertentes principais que as pesquisas em curso, neste domínio, permitem perceber.

Este texto foi submetido a seis especialistas, cujos comentários são seguidos pela resposta da Autora. Unitermos: Corpo. História do corpo. História cultural. Nova História social.

Anais do Museu Paulista, n.sér. y.3, p.9-26, 1995.

Dossier: History of the human body

Mary Lucy Muray del Priore

This article, intended as a text for debate, is a collection of views on the ways the human body has been represented in History. Subjects discussed range from Anthropology to Literature and include New Social History, History of Medicine and Art History. Although neither an exhaustive survey nor a systematic study of a compact domain in the History of the human body, it attempts to reflect a crossdisciplinary diversity of approaches and to point out the main trends exhibited by the ongoing research on the matter.

This text has been submitted to six specialists whose commentaries are followed by the Author's reply. Uniterms: Body. History of the human body. Cultural History. New Social History. Anais do Museu Paulista, n.sér.v.3, p.9-26, 1995.

Do Teatro da Memória ao Laboratório da História: a exposição museológica e o conhecimento histórico. Debate (fim)

Ulpiano T. Bezerra de Meneses

Resposta aos comentários de dez especialistas que contribuíram no debate de texto publicado no último número desta revista. A discussão orientou-se segundo seis tópicos principais: museus históricos, identidade, ideologia e a categoria de nação; a necessidade de acervos materiais e suas modalidades: acervo patrimonial, operacional, virtual; teatro versus laboratório; o público e suas ambigüidades; História Pública: o museu e a Academia.

Unitermos: Museu histórico. História e exposição museológica

Anais do Museu Paulista, n.sér., v.3, p.103-122, 1995.

From the Theater of Memory to the Laboratory of History: museological exhibits and historical knoledge. A debate (end).

Ulpiano T.Bezerra de Meneses

Reply to ten comments on a paper published in the last issue of this journal. The discussion follows along six main lines: History museums, identity, ideology and the category of nation; the need of material collections and their modalities: patrimonial, operational, virtual; theater versus laboratory; visitors and their ambiguities; Public History: the museum and the academy.

Uniterms: History museum. History and museological exhibits.

Anais do Museu Paulista, n.sér., v. 3, p. 103-122, 1995. 